\title{
Clinical features and histological types of 35 cases of carcinoma esophagus: experience from two hospitals in Bangladesh
}

\author{
Md. Nazmul Hoque ${ }^{1}$, Md. Forhadul Islam Chowdhury ${ }^{2}$, \\ Shireen Ahmed ${ }^{1}$, Md. Abdullah Al Mamoon ${ }^{1}$ \\ ${ }^{1}$ Department of GHPD, BIRDEM General Hospital, Dhaka, Bangladesh; \\ ${ }^{2}$ Department of GHPD, East West Medical College, Turag, Uttara, Dhaka, Bangladesh
}

\begin{abstract}
Background and objectives: Esophageal malignancy is a fatal disease. Squamous cell cancer and adenocarcinoma are two most common types. The present study aimed to describe demographic characteristics, clinical features, histological types and associated among the selected Bangladeshi patients with esophageal cancers.

Methods: This cross-sectional descriptive study was conducted from January to December 2016 at two hospitals in Bangladesh. Total 35 adult patients diagnosed as having esophageal cancer were consecutively and purposively included in this study. Age, gender, history of chewing betel nut and smoking, clinical presentation and laboratory parameters were recorded systematically in a predesigned data sheet.

Results: Among the 35 patients with esophageal cancer, $80 \%$ were more than 50 yrs of age while $71.4 \%$ and $28.6 \%$ were male and female respectively. Out of these cases, $27(77.1 \%)$ had squamous cell carcinoma (SCC) and 8 (22.9\%) had adenocarcinoma. Out of 27 SCC, 15 $(55.6 \%)$ had lesion in mid-esophagus, $9(33.3 \%)$ in lower and $3(11.1 \%)$ in upper esophagus. All adenocarcinoma were present in lower esophagus. History of smoking and chewing betel nut were not significantly associated with esophageal cancers.

Conclusions: Esophageal carcinoma was common in elderly male and SCC was more frequent compared to adenocarcinoma. Further study with larger number of samples is required to determine the role of smoking and betel nut chewing in esophageal cancers in Bangladeshi population.
\end{abstract}

IMC J Med Sci 2017; 11(2): 36-39

\section{Introduction}

Esophageal cancer usually presents at an advanced stage, and thus curative treatment is limited and the prognosis is poor [1]. In spite of the recent development in cancer therapy, esophageal cancer remains one of the least treatment-responsive malignancies [2]. Even in developed countries, more than $85 \%$ of patients die within two years of diagnosis, making it the sixth most common cause of cancer-related deaths in the world [3]. The main histologic types of esophageal cancer are squamous cell carcinoma (SCC) and adenocarcinoma [4]. Esophageal cancer is generally more common in men than in women. The male-to-female ratio is 3 to $4: 1$. Esophageal cancer occurs most commonly during the sixth and seventh decades of life [5]. Approximately, $50 \%$ to $60 \%$ of squamous cell esophageal cancers occur in the middle third of the esophagus, $33 \%$ involve the distal esophagus, and $10 \%$ occur in the proximal esophagus [6]. In Western cultures, retrospective evidence has implicated cigarette smoking and chronic alcohol 
exposure as the most common etiologic factors for squamous cell carcinoma [7]. High body mass index, gastro esophageal reflux disease (GERD), and resultant Barrett esophagus are often the associated factors for esophageal adenocarcinoma $[8,9]$. Caustic injuries, betel nut, certain fungus and smoking have been implicated to promote esophageal cancer in south Asia $[10,11]$.

Therefore, a better understanding of the sociodemographic characteristics, etiology and risk factors of esophageal cancer would be useful for its primary prevention [12,13]. At present, only limited information is available on esophageal cancer among Bangladeshi population. [14]. Therefore, the present study aimed to describe the demographic characteristic, clinical presentation, histological types of esophageal cancer among selected Bangladeshi patients.

\section{Methods}

This cross-sectional descriptive study was conducted from January to December 2016 at two hospitals of Bangladesh located in Feni district and Dhaka city. Feni district is located $128 \mathrm{~km}$ from Dhaka city in the south-eastern part of Bangladesh. Endoscopicaly diagnosed 35 adult consecutive cases of esophageal carcinoma were included. In this study either sex was consecutively and purposively included. Previously diagnosed case of carcinoma esophagus under treatment and patients with inconclusive histological findings were excluded from the study. Age, gender, history of chewing betel nut and smoking, clinical presentation and laboratory parameters were recorded systematically in a predesigned data sheet. Upper gastrointestinal (GI) endoscopy was done by Olympus CV 150 machine and 6 to 8 pieces of tissues were taken by Olympus biopsy forceps. Collected tissue was immersed in formalin container for histopathology examination. Histopathology was done by experienced pathologists. Patients were initially classified as esophageal cancer by gross endoscopic findings and later confirmed by histopathology examination. The data were presented as percentage and mean and relevant statistical tests were employed to determine significant association or differences among variables.

\section{Results}

A total of 35 consecutive cancer esophagus cases were enrolled. The mean age was 61.3 years and the range was 40 to 85 years while $80 \%$ were more than 50 years of age (Table-1). Of the 35 cases, $71.4 \%$ was male and $28.6 \%$ was female. Regarding the status of smoking it was found that $19(54.3 \%)$ were either smoker or ex-smoker (Table I). Among the 35 cases, overall $62.9 \%$ cases had the history of betel nut chewing irrespective of the types of esophageal cancer. All the patients having esophageal cancer had dysphagia, of which $19(54.3 \%)$ patients had relative dysphagia (dysphagia only for solid foods) and remainder $16(45.7 \%)$ patients had absolute dysphagia (both solid and liquid; Table-2). The mean duration of the symptoms was 1.4 months. Out of 35 cases, $27(77.1 \%)$ had SCC and 8 (22.9\%) had adenocarcinoma by histological examination (Table-2). Endoscopic examination revealed that all adenocarcinoma were present in the lower part of the esophagus. Out of 27 SCC, $15(55.6 \%)$ had lesion in mid-esophagus, 9 $(33.3 \%)$ in lower and $3(11.1 \%)$ in upper esophagus (Table-2). Table-3 shows that the habit of betel nut chewing was present in higher proportion of patients $(70.4 \%$; 19/27) with SCC compared to patients with adenocarcinoma (37.5\%); $3 / 8)$. But the difference was not significant $(\mathrm{p}=$ 0.0907). On the other hand, history of smoking was present in $75 \%$ of cases with adenocarcinoma compared to $48.1 \%$ in cases with SCC. But the difference was not statistically significant (0.1782).

Table-1: Baseline characteristics of 35 esophageal cancer cases

\begin{tabular}{lcc}
\hline \multicolumn{1}{c}{ Characteristics } & Number & \% \\
\hline Age (yrs) & & \\
$\quad>50$ & 28 & 80.0 \\
$\leq 50$ & 7 & 20.0 \\
Male & 25 & 71.4 \\
Female & 10 & 28.6 \\
Smoker/ Ex smoker & 19 & 54.3 \\
Non-smoker & 16 & 45.7 \\
Betel nut user & 22 & 62.9 \\
Betel nut non-user & 13 & 37.1 \\
\hline
\end{tabular}


Table-2: Major clinical features, endoscopic and histological findings of the study population

\begin{tabular}{lcc}
\hline \multicolumn{1}{c}{ Description } & Number & $\%$ \\
\hline Clinical feature $(\mathrm{n}=35)$ & & \\
Absolute dysphagia & 16 & 45.7 \\
Relative dysphagia & 19 & 54.3 \\
& & \\
Histological types of tumor & & \\
$\begin{array}{l}\text { Squamous cell carcinoma } \\
\text { Adenocarcinoma }\end{array}$ & 27 & 77.1 \\
& 8 & 22.9 \\
Site of SCC (n=27) & & \\
Upper esophagua & 3 & 11.1 \\
Mid esophagus & 15 & 55.6 \\
Lower esophagus & 9 & 33.3 \\
Site of adenocarcinoma $(\mathrm{n}=8)$ & & \\
Lower esophagus & 8 & 100.0 \\
\hline
\end{tabular}

Table-3: Betel nut chewing and smoking habits of study population with SCC and adenocarcinoma

\begin{tabular}{lccc}
\hline \multicolumn{1}{c}{$\begin{array}{c}\text { Type of } \\
\text { carcinoma }\end{array}$} & $\begin{array}{c}\text { Total } \\
\text { number } \\
\text { of cases }\end{array}$ & $\begin{array}{c}\text { Had } \\
\text { habit of } \\
\text { betel nut } \\
\text { chewing }\end{array}$ & $\begin{array}{c}\text { Had } \\
\text { habit of } \\
\text { smoking }\end{array}$ \\
\cline { 3 - 4 } & & $\mathbf{N}(\%)$ & $\mathbf{N}(\%)$ \\
\hline $\begin{array}{l}\text { Squamous cell } \\
\text { carcinoma }\end{array}$ & 27 & $19(70.4)$ & $13(48.1)$ \\
$\begin{array}{l}\text { Adenocarcinoma } \\
\text { p value }\end{array}$ & 8 & $3(37.5)$ & $6(75.0)$ \\
\hline
\end{tabular}

Note: Z-test was employed to calculate $p$ value.

\section{Discussion}

Worldwide esophageal cancer is the sixth leading cause of death due to cancer, accounting for about $5 \%$ (407,000 deaths) of all cancer deaths annually. It is the eighth most common cancer worldwide [12]. The treatment for esophageal cancer is protracted and is fatal in a significant number of cases. Therefore, in the current study we have tried to elucidate the socio-demographic characteristics, possible associated factors and histological types of esophageal cancer among Bangladeshi population.

In this study we have found that $80 \%$ cases had age more than 50 years. In the United States from 2001 to 2005 , the median age at diagnosis for cancer of the esophagus was 69 years [15]. In high incidence regions, the disease has no gender specificity, while SCC is more common in men in low incidence region [16]. In our study, we have found that out of 35 esophageal cancer cases, $71.4 \%$ was male.

It has been reported that in the United States, the incidence of esophageal SCC is decreasing whereas the rate of adenocarcinoma is rising dramatically [17]. But in our series, squamous cell carcinoma was more common (77.1\%) compared to adenocarcinoma $(22.9 \%)$ and we have found that the majority $(55.5 \%)$ of the SCC were at the middle third of the esophagus, which correlates with other study [18].

Chewing of betel nuts or betel quid (areca nuts wrapped in betel leaves), which is widespread in certain regions of Asia, have been implicated in the development of esophageal SCC $[19,20]$. Though we have found that higher proportion $(70.4 \%)$ of cases of SCC had history of using betel nut compared to adenocarcinoma (37.5\%), the difference was not statistically significant $(\mathrm{p}=0.0907)$. Further case control or cohort study with larger number of study population is required to find out whether betel nut chewing is a risk factor for SCC in our population. In our study, about half of the patients (54.3\%) were smoker and the rate of smoking was higher in patients with adenocarcinoma compared to cases with SCC. But there was no significant $(\mathrm{p}=0.1782)$ association of adenocarcinoma with smoking habit (Table-3).

Current study had some potential limitations. It was a descriptive cross-sectional small scale study with only 35 samples from two centers. We recommend that further prospective cohort or case control studies with larger sample should be undertaken to find out whether betel nut chewing and smoking are potential risk factors for esophageal cancer in Bangladeshi population.

Conflict of interest: None declared.

\section{References}

1. Jemal A, Siegel R, Xu J, Ward E. Cancer statistics, 2010. CA Cancer J Clin. 2010; 60: 277-300. 
Hoque MN et al.

2. Enzinger PC, Mayer RJ. Esophageal cancer. N Engl J Med. 2003; 349(23): 2241-2252.

3. Kamangar F, Malekzadeh R, Dawsey SM, Saidi F. Esophageal cancer in North Eastern Iran: A review. Arch Iran Med. 2007; 10: 70-82.

4. World Health Organization classification of tumour. Pathology and genetics of tumours of the digestive system. Lyon, France International Agency for research on cancer; 2000. 314 p Report no. 9-30.

5. Kirby TJ, Rice TW. The epidemiology of esophageal carcinoma. The changing face of a disease. Chest Surg Clin N Am. 1994; 4(2): 217-25.

6. Park K. Park's Text Book of Preventive and Social Medicine. $21^{\text {st }}$ ed. Jabalpur: M/S Banarasidas Bhanot Publishers; 2011; p110112.

7. Steevens J, Schouten LJ, Goldbohm RA, Van den Brandt PA. Alcohol consumption, cigarette smoking and risk of subtypes of esophageal and gastric cancer: a prospective cohort study. Gut. 2010; 59(1): 39-48.

8. Lagergren J, Bergström R, Lindgren $A$, Nyrén O. Symptomatic gastroesophageal reflux as a risk factor for esophageal adenocarcinoma. $N$ Engl J Med. 1999; 340(11): 825-31.

9. O'Doherty, MG(1), Freedman ND, Hollenbeck AR, Schatzkin A, Abnet CC. A prospective cohort study of obesity and risk of esophageal and gastric adenocarcinoma in the NIHAARP Diet and Health Study. Gut. 2012; 61: 1261-8.

10. Kubo A, Corley DA. Body mass index and adenocarcinomas of the esophagus or gastric cardia: a systematic review and meta-analysis. Cancer Epidemiol Biomarkers Prev. 2006; 15(5): 872-878.

11. Kabat GC, Ng SK, Wynder EL. Tobacco, alcohol intake, and diet in relation to adenocarcinoma of the esophagus and gastric cardia. Cancer Causes and Control. 1993; 4(2): $123-32$.
12. American Cancer Society. Cancer Facts \& Figures 2016. Atlanta America; American cancer society; August $8.72 \mathrm{p}$ Report no 25.

13. Gammon MD. Schoenberg JB. Ahsan H. Risch HA. Vaughan TL. Chow WH. Rotterdam H. et al. Tobacco, alcohol, and socioeconomic status and adenocarcinomas of the esophagus and gastric cardia. J Natl Cancer Inst. 1997; 89: 1277-1284.

14. Parveen R, Rahman S S, Sultana S A, Hossain Z. Cancer Types and Treatment Modalities in Patients Attending at Delta Medical College Hospital. Delta Med Col J. 2015; 3(2): 57-62.

15. National cancer institute. Surveillance, epidemiology and end results program: Cancer statistics review 1975-2005. Bethesda: National cancer institute; 2008. 29p report 8.

16. Pottern LM, Morris LE, Blot WJ, Ziegler RG, Fraumeni JF. et al. Esophageal cancer among black men in Washington, D.C. Alcohol, tobacco, and other risk factors. $J$ Natl Cancer Inst. 1981; 67: 75 -77.

17. Pohl H, Sirovich B, Welch HG. Esophageal adenocarcinoma incidence: are we reaching the peak? Cancer Epidemiol Biomarkers Prev. 2010; 19: 1468.

18. Hölscher AH, Bollschweiler E, Schneider PM, Siewert JR. Prognosis of early esophageal cancer. Comparison between adeno- and squamous cell carcinoma. J Cancer. 1995; 76: 178.

19. Pickwell SM, Schimelpfening S, Palinkas LA. 'Betelmania'. Betel quid chewing by Cambodian women in the United States and its potential health effects. West J Med. 1994; 160: 326.

20. Akhtar S, Sheikh AA, Qureshi HU. Chewing areca nut, betel quid, oral snuff, cigarette smoking and the risk of oesophageal squamous-cell carcinoma in South Asians: a multicentre case-control study. Eur J Cancer. 2012; 48: 655. 